Original Research Paper

\title{
Investigating the Dynamic Thermal Behavior of Building Envelope in Summer Conditions By Means of in-Field Continuous Monitoring
}

\author{
${ }^{1,2}$ Anna Laura Pisello, ${ }^{1}$ Gloria Pignatta, ${ }^{1}$ Cristina Piselli, ${ }^{1}$ Veronica Lucia Castaldo and ${ }^{1,2}$ Franco Cotana \\ ${ }^{I}$ CIRIAF-Interuniversity Research Center on Pollution and Environment "M. Felli", University of Perugia, Perugia, Italy \\ ${ }^{2}$ Department of Engineering, University of Perugia, Perugia, Italy
}

\author{
Article history \\ Received: 11-04-2016 \\ Revised: $15-04-2016$ \\ Accepted: 23-04-2016 \\ Corresponding Author: \\ Gloria Pignatta \\ CIRIAF-Interuniversity \\ Research Center on Pollution \\ and Environment "M. Felli", \\ University of Perugia, Perugia, \\ Italy \\ Email: pignatta@crbnet.it
}

\begin{abstract}
The effect of dynamic properties of building opaque envelope in summer conditions is investigated by means of an extensive continuous monitoring of a dedicated experimental field. Two testbuildings, a weather station and two microclimate stations positioned in each test-building represent the experimental field. The prototype buildings have been specifically designed to present the same stationary envelope properties, but different construction techniques and materials, therefore behaving differently in real dynamic conditions. Building upon a previous study by the authors, also in summer conditions, the main results of this research show a non-negligible difference of the dynamic hygro-thermal behavior of the two Test-Rooms. Significant differences in terms of indoor air temperature, envelope surface indoor/outdoor temperatures and indoor air humidity are detected, due to the difference in the dynamic envelope properties of the two TestRooms, i.e., thermal mass, solar reflectance of the external skin and transpiration capability. Also, the overall discrepancy is detected to be higher in summer than in winter conditions, given the higher influence of the outdoor weather forcing boundaries such as solar radiation.
\end{abstract}

Keywords: Building Envelope, In-Field Continuous Monitoring, Building Thermal Performance, Indoor Thermal Behavior, Frequency Analysis, Summer Performance

\section{Introduction}

Given the large amount of global energy demand associated to the construction sector, the interest around buildings energy efficiency is increasingly growing. In the European Union about the $40 \%$ of the total energy consumed in terms of primary energy is associated to buildings (Asdrubali et al., 2008), mainly for ventilation, air conditioning and humidity control purposes (Salata et al., 2014a; Tariku et al., 2015). Therefore, improving the thermal-energy performance of buildings is a point of strength within the set of measures necessary to reduce global energy demand and, consequently, environmental impact in terms of greenhouse gas emissions and air pollution (Evangelisti et al., 2014). In particular, the optimization of the performance of building envelope plays a key role in reducing the overall building thermal-energy requirement. In fact, it is usually a consequence of poor thermal insulation (Saber et al., 2015) and high solar absorption characteristics of building fabric (Peruzzi et al., 2014; Synnefa and Santamouris, 2012).

National standards generally focus on winter heating consumption, leading to iper-insulated envelopes acting as thermal barriers even when it is not much required by the climatic context (Stazi et al., 2014). This strategy causes increasing phenomena of summer overheating (Kolokotsa and Santamouris, 2015) and the increasing necessity of cooling systems for the regulation of indoor comfort in summer. In last decades, even in traditionally considered heating-dominated climates, the percentage of cooling demand in the net energy demand has increased (Grynning et al., 2014), as a consequence of the global warming. In particular, the problem of energy consumption is evident in temperate climates where the cooling load is as important as the heating 
load (Znouda et al., 2014). Accordingly, the European regulations such as the Directives 2010/31/EU (OJEU, 2010) and 2012/27/EU (OJEU, 2012) highlighted the importance of considering the specific external and internal climatic conditions while assessing the efficacy of the measures for buildings energy saving, enhancing the summer performance (Stazi et al., 2014). Furthermore, the mentioned standards underestimate the thermal inertia of the building, since the energy analysis is carried out through semi-stationary methods under steady-state conditions (Evangelisti et al., 2014). Nevertheless, more complex transient evaluation tools are needed in order to assess the effect of envelope improvements and innovative strategies on indoor comfort and energy requirements (Stazi et al., 2014), i.e., dynamic analysis methods. For instance, De Lieto Vollaro et al. (2015) carried out a comparative analysis of the energy performance of an old building by implementing semi-stationary and dynamic tools, finding out non-negligible discrepancies.

A careful analysis of the complex thermo-physical properties of opaque and transparent components of building envelope requires indoor-outdoor environmental monitoring of real case studies. Dynamic testing allows to analyze dynamic processes and to identify the main parameters affecting the physical process (Salata et al., 2014b). Both dynamic testing and analysis methods are needed to thoroughly qualify and quantify the thermal-energy performance of building components (Baker and Van Dijk, 2008). In this view, Kotsiris et al. (2012) evaluated the thermal transmittance coefficient of various green roof systems in real scale and under dynamic conditions. Then, they simulated the green roof systems when applied to an existing building in order to quantify their energy behavior.

According to the need of studying the behavior of building components and systems under real dynamic conditions, during last decades several researches developed dedicated full-scale test-buildings. Due to their relative simplicity, compared to a real building, such test cells allow greater control on the dynamic parameters that affect their thermal-energy performance, showing more accurate results. In fact, test cells provide a well-controlled, realistic room sized environment without occupants' effects (Pisello et al., 2015), which are widely acknowledged to be a key factor influencing thermal-energy requirement in buildings (Hong et al., 2015). In this panorama, a key contribution is the European PASSYS Project (Passive Solar Components and Systems Testing) aimed at designing a test cell useful to study energy efficient and passive solar building products (Baker and Van Dijk, 2008). The test cell was designed in order to reach the maximum adiabatic condition in all walls except for the testing wall. Several interesting researches have been developed to follow up the results obtained for this topic. In particular, the PASSLINK Network developed and improved test methods and analysis procedures to obtain thermal and solar characteristics of building components under real dynamic outdoor conditions (Baker and Van Dijk, 2008).

Various previous studies have employed a PASSLINK test facility in order to assess the efficiency of different building opaque and transparent components (Leal and Maldonado, 2008). Alcamo and De Lucia (2014) adopted a test cell, located in Florence, Italy, in order to evaluate the thermal behavior under real climatic conditions of new building façade components, i.e., ventilated walls, PCMs and others, using nano-technologies and aerogels. Results of this study are intended to be used to write new algorithms for dynamic simulation tools allowing an appropriate evaluation of such complex systems behavior. Additionally, test cells are often used to assess the performance under real dynamic conditions of green roofs and cool materials. Indeed, these systems are generally expensive to be implemented in existing buildings. For instance, Kotsiris et al. (2012), as already mentioned, compared the thermal performance of different green roofs under dynamic conditions when applied to an upgraded PASLINK test cell. Doya et al. (2012), instead, experimented the performance of cool façades in a confined environment similar to an urban scene, to assess their potentiality in mitigating Urban Heat Island. A key experimental field is also implemented in Spain where the large number of cubicles allows to perform always parallel measurements in order to comparatively evaluate the effect of an energy efficiency strategy with respect to the reference building located within the same installation (Coma et al., 2016).

Consistently, the experimental field presented in this study was set up in order to assess the comparative performance of traditional and new envelope technologies and building systems. Therefore, it includes two full-scale test-buildings, i.e., Test-Rooms (TR). TR1 was designed by following the typical Italian construction practice, while TR-2 was characterized by more recent Italian construction typicality, i.e., with external coat system. Nevertheless, these buildings are characterized by exactly the same geometry and stationary properties of the multilayer envelope systems and HVAC systems. The feature that characterizes the Test-Rooms compared to similar experimental fields is the use of complete envelope solutions and realistic conventional materials, e.g., terracotta bricks, cement based plasters and reinforced concrete structure, in order to represent typical configurations of existing buildings. In this way, the influence of dynamic properties of building components, such as (a) envelope reflectance 
(Doya et al., 2012; Revel et al., 2014), (b) thermal inertia (Evangelisti et al., 2014), or (c) walls-roof-ceiling layers position (Stazi et al., 2014; Bond et al., 2013; Kossecka and Kosny, 2002), which are neglected in regulations for building design in Italy, can be evaluated. In particular, the present study has the aim of comparing the effect of such envelope properties in the hygro-thermal behavior of the test-buildings in summer conditions.

This study builds upon the previous work carried out by Pisello et al. (2014) in winter conditions, through an integrated approach involving the analysis of envelope performance in summer.

\section{Scope of the Work}

This work is part of a more extensive experimental research aimed at evaluating the thermal-energy performance of different envelope typologies presenting the same stationary thermal properties, through continuous monitoring of indoor and outdoor environmental conditions (Pisello et al., 2014). Additionally, it could be considered as one of the useful works for the scientific community interested in making indoor-outdoor microclimate optimization by means of continuous monitoring campaign carried out within full-scale test buildings (Navarro et al., 2915; De Gracia et al., 2015). The field continuous monitoring campaign started in 2012, when the two Test-Rooms constructions were built. The full-scale test-buildings were conceived with the purpose of being representative of Italian typical building technique, i.e., Test-Room 1 and Italian new construction technique, i.e., Test-Room 2. In this view, the building components of both Test-Rooms are easily modifiable and the field tests are designed to be integrated with in-lab tests by means of hot-box apparatus, for instance. Additionally, the indoor monitoring system was also linked to a dedicated outdoor weather station for developing a sort of coupled indoor-outdoor continuous monitoring of building thermal-energy performance in dynamic real conditions. Further details on the envelope characteristics and the monitoring setup are explained in the following section. Previous works by the authors (Pisello et al., 2014 ; 2015) report the key architectural and technical parameters, typical of residential houses and the installation positioning, properly designed in order to avoid mutual shading phenomena during the course of the year. In Pisello et al. (2014), building thermal performance in winter conditions is investigated, while this work deals with the dynamic analysis of the same envelope typologies under summer conditions, thus completing the annual performance evaluation. Findings of this study are expected to be consistent with the previous one and even more significant, due to the greater contribution of solar radiation in summer.

\section{Materials and Methods}

In order to assess the dynamic hygro-thermal performance of different building components, technologies and systems, the comparative analysis of the two Test-Rooms, equivalent in terms of envelope thermal properties in steady-state, has been carried out. However, the properties simplification of Test-Rooms compared to real buildings, in terms of geometry, produces unavoidable inaccuracies. Therefore, in this study the analysis is carried out through comparison between the two Test-Rooms to exclude such inaccuracies, which are the same for both TestRooms. The compared performance of Test-Rooms is here investigated in summer conditions by taking into account the results of continuous monitoring. The analysis is carried out in two main operating regimes, i.e., (a) transient regime and (b) free floating regime, since no considerable data of the operating system behavior were available. Particularly, the behavior of each building is assessed in terms of indoor hygrothermal conditions, i.e., air temperature (Tair), operative temperature (Top), mean radiant temperature (Tmr) and air relative humidity profiles during the two investigated regimes.

Furthermore, the frequency analysis is carried out in order to evaluate the cyclic thermal behavior of the two Test-Rooms in free-floating regime. To this aim, the frequency spectrum is calculated for the outdoor thermal forcing, i.e., outdoor air temperature and for both the Test-Rooms indoor air temperature.

Finally, the thermal behavior of opaque envelope elements is studied through the analysis of surface temperature and thermal flux through South and Northfacing walls and roof. The main characteristics of both buildings and monitoring setup are reported in the following two sub-sections and the frequency analysis methodology is presented in the last sub-section.

\section{Test-Rooms Experimental Field}

The Test-Rooms indoor-outdoor laboratory field is located in central Italy (Fig. 1), according to the land availability in the installation area and by achieving no mutual shading between the two buildings and the absence of any external shading objects. From a technical point of view, the two Test-Rooms were specifically designed in order to present the same ex-ante stationary thermal characteristics of both the transparent and opaque envelope elements. Therefore, the walls and ceilings thermal transmittance and the superficial mass is equivalent for both the buildings, but the stratigraphy design changes. More in details, Test-Room 1 (TR-1) presents a double brick block layer façade with the insulation in the wall cavity and a ventilated roof with internal insulation and red clay tiles. Test-Room 2 (TR-2) 
is characterized by plastered walls brick color coated with external insulation panel and horizontal roof also with external insulation panel and bitumen waterproof membrane as finishing material. The calculated thermal transmittance $(\mathrm{U})$ is equal to $0.29 \mathrm{~W} / \mathrm{m}^{2} \mathrm{~K}$ and $0.25 \mathrm{~W} / \mathrm{m}^{2}$ $\mathrm{K}$ for wall and roof. The same wooden door is located within the North facing wall of the buildings and the same window and shutter system are positioned within their South facing facades.

More detailed information on envelope components and energy systems are described in Pisello et al. (2014).

\section{The Continuous Monitoring System}

The monitoring equipment (Fig. 2) was installed in 2012 and it is still operating for monitoring both indoor and outdoor conditions. The system consists of (a) environmental and thermal parameters sensors, (b) energy meters, (c) data-loggers, (d) converters and (e) an indoor permanent server station (Pisello et al., 2014). The outdoor meteorological station is also connected within the lab dedicated to this research (Test-Room lab) and it is located in close proximity to the Test-Rooms. It allows to continuously measure the weather conditions of the specific site in terms of air temperature trends, air relative humidity, wind speed and direction, precipitation characterization, solar radiation profiles, etc.

The two twin indoor monitoring setups, i.e., one in each Test-Room, measure (a) the indoor air hygrothermal conditions, (b) the envelope performance in terms of internal and external surface temperatures and thermal flux of roof and walls, (c) the reflected radiation by the roof and (d) the energy consumption of the
HVAC system (Pisello et al., 2014). In particular, thermal flux sensors are positioned on the internal ceiling surface and on the internal North-facing wall surface of the two Test-Rooms. The measurement frequency has been set every $20 \mathrm{sec}$ for all the sensors with an exception for the wind sensors that measure every $5 \mathrm{sec}$. Then, the post-process controller calculates the minimum, maximum, average and standard deviation values every $10 \mathrm{~min}$.

Further information on the indoor-outdoor monitoring setup and, in particular, the description of sensors and measured parameters are depicted in Pisello et al. $(2014 ;$ 2015).

\section{Frequency Analysis}

The representation of temperature signals under time-domain gives information about the amplitude of the signal at the instants of time when it was sampled. However, no information is provided about the periodic behavior of the signal. For this reason, the frequency content of the temperature signals is here evaluated through the frequency-domain representation, where the periodic behavior of temperature fluctuation is highlighted. Additionally, frequency-domain representation provides details on the phase shift also from a comparative perspective while analyzing the two Test-Rooms.

The present analysis considered a set of air temperature measurements, i.e., the outdoor dry-bulb temperature (Tout) and the air temperature inside the two Test-Rooms (Tair_1 and Tair_2), monitored during summer in free-floating conditions, i.e., in the period July 29th-August 18th, 2013.
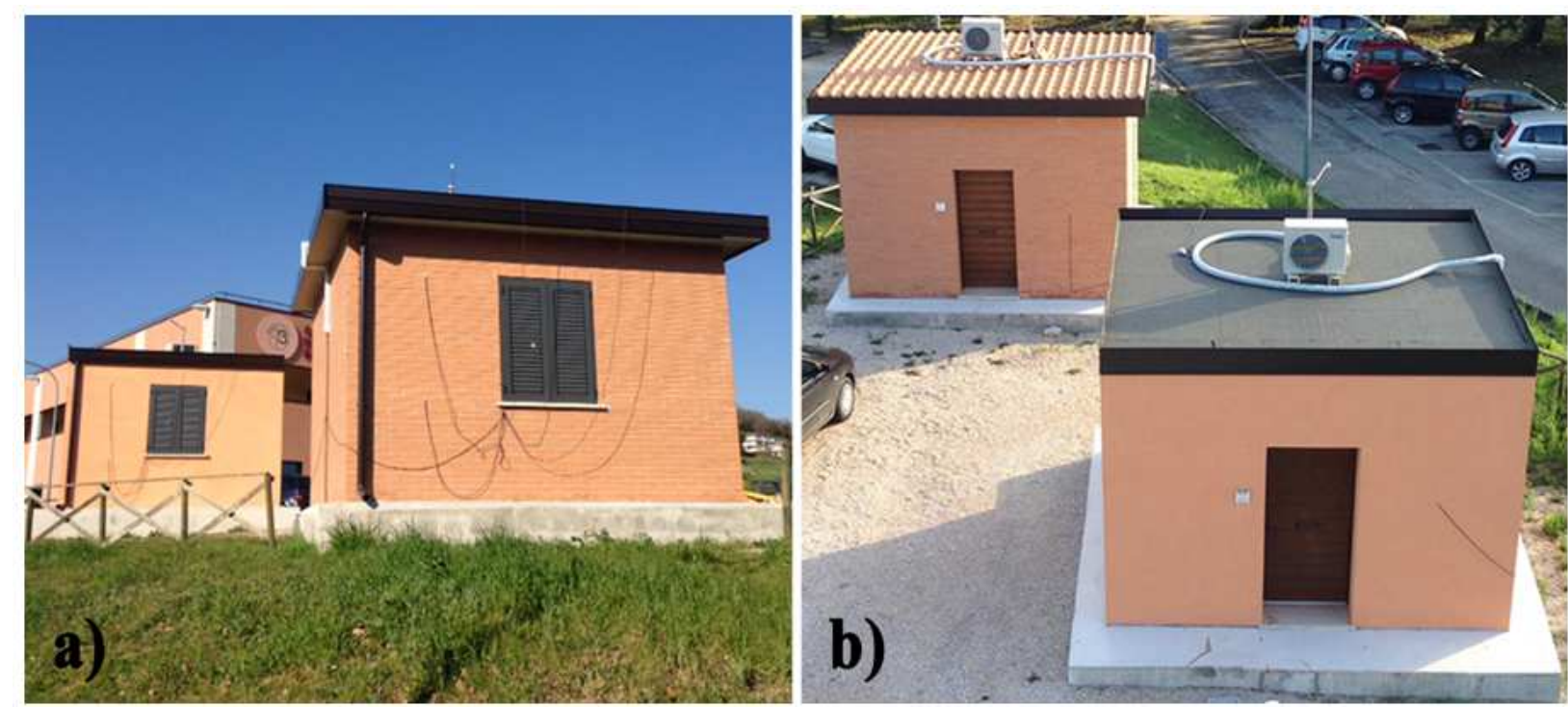

Fig. 1. Test-Rooms experimental field: (a) South view and (b) North view of Test-Room 1 and Test-Room 2 

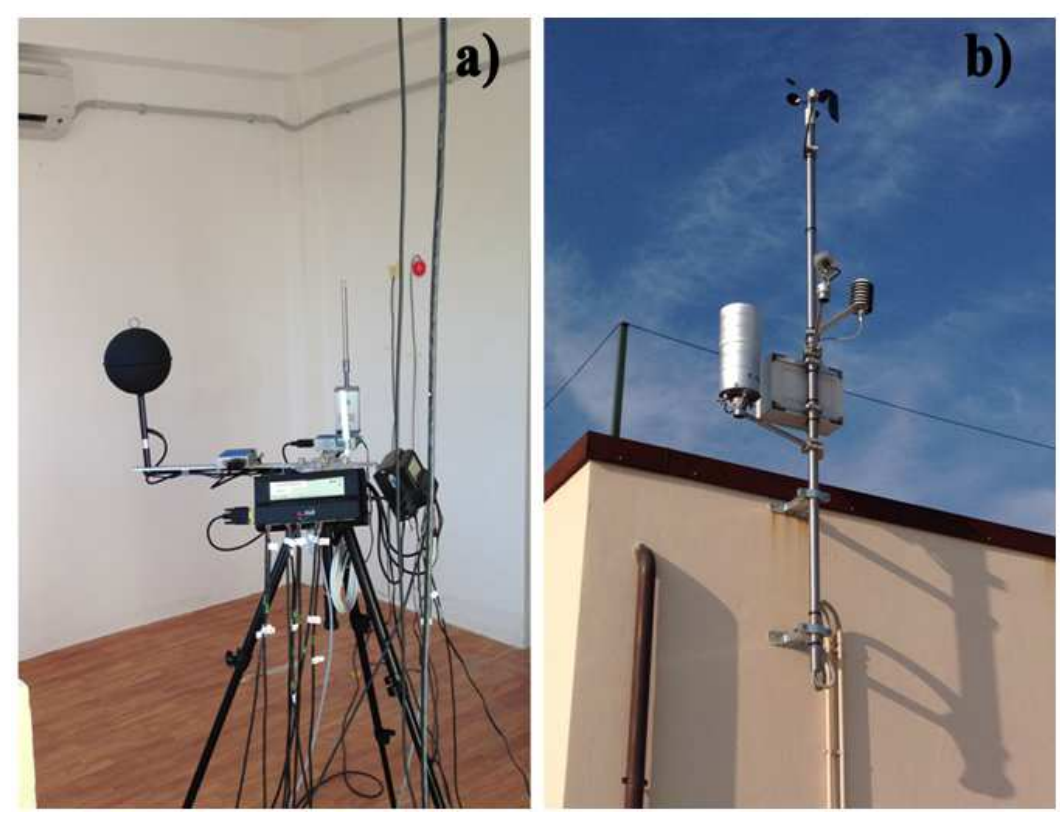

Fig. 2. Monitoring equipment: (a) indoor microclimatic and (b) meteorological stations

The Fourier transform was here applied to convert the thermal signals, i.e., Tout, Tair_1 and Tair_2, from the time $(\mathrm{T}(t))$ to the frequency domain $(\Theta(f))$. The Fourier transform $\Theta(f)$ of the continuous thermal time function $\mathrm{T}(t)$ is described in Equation 1:

$$
\Theta(f)=\int_{-\infty}^{+\infty} T(t) \cdot e x t^{-j 2 \pi f t} d t \quad\left[{ }^{\circ} \mathrm{C} \mathrm{sec}\right]
$$

In particular, the Fast Fourier Transform (FFT) function in MATLAB was here applied to each evaluated thermal signal. In this study, the result of the FFT computation is a complex number $(\Theta)$ characterized by a real part $\left(\Theta_{r}\right)$ and an imaginary part $\left(\Theta_{i}\right)$ as reported in the Equation 2 below:

$$
\Theta=\Theta_{r}+i \cdot \Theta_{i}
$$

Equation 2 contains information about the frequency content of the signal, such as magnitude and phase spectrum. Therefore, magnitude $\left(M_{T}\right)$, which corresponds to the amplitude and phase $\left(P_{T}\right)$, which corresponds to the angle of $\Theta$, of the thermal signal were calculated in this study as follows, in Equation 3 and 4:

$$
\begin{aligned}
& M_{T}=\sqrt{\left(\Theta_{r}^{2}+\Theta_{i}^{2}\right)} \quad[-] \\
& P_{T}=\operatorname{arctg}\left(\Theta_{i}+\Theta_{r}\right) \quad[\mathrm{rad}]
\end{aligned}
$$

The sampling and truncation of the signal are two of the fundamental operations necessary to perform a reliable frequency analysis. The sampling theorem is expressed by Equation 5:

$$
f_{s} \geq 2 \cdot f_{\max }
$$

As previously mentioned, the sampling of the air temperature measurements was performed every 10 minutes. Therefore, the frequency sampling $f_{s}$ is equal to $0.16 \cdot 10^{-2} \mathrm{sec}^{-1}$, while the maximum frequency $f_{\max }$ included in the signals is equal to $0.83 \cdot 10^{-3} \mathrm{sec}^{-1}$. In this study, the sampling theorem is satisfied. Regarding the truncation of the signals, a limited temporal window of 21 days was considered with the hypothesis that the monitored temperature data are repeated indefinitely over time.

The cyclicality of the thermal signals is indicated with the period that represents the duration of the $i$ th cycle. The reciprocal of the frequency $f_{i}$, which corresponds to the $i$ th peak of magnitude, i.e., period Ti, is calculated as expressed in the Equation 6:

$T_{i}=1 / f_{i} \quad[\mathrm{sec}] \quad i=1,2, \ldots, N$

where, $N$ is the maximum number of cycles and frequencies considered in this study, i.e., $N=5$.

\section{Results and Discussion}

In this section, the results of the continuous monitoring are analyzed in terms of indoor hygrothermal behavior and envelope performance of the TestRooms. The assessment is carried out by taking into account the two main operational regimes, i.e., (a) the transient regime and (b) the free-floating regime. 
In order to compare the Test-Rooms hygro-thermal performance, the analysis of indoor air temperature, operative temperature, mean radiant temperature and indoor air relative humidity profiles is performed for each building, during the two investigated regimes. The comparison in terms of thermal behavior is performed through both the time analysis and the frequency analysis. Moreover, the thermal performance of opaque envelope components, i.e., roof and walls, is assessed through thermal flux and surface temperature analysis.

\section{Indoor Thermal Behavior: Transient Period}

The analysis of the indoor thermal behavior of the two Test-Rooms in transient regime has been carried out for the twelve-day period following the heat pump switching off on April 30th, 2013. The registered transient cooling path, measured every $10 \mathrm{~min}$ in terms of operative temperature, air temperature and mean radiant temperature, is reported in Fig. 3. The downward trend of indoor temperatures is due to the still cool weather conditions registered in May. A significant correlation is shown by comparing the two Test-Rooms that present similar behavior during the transient period. In both TR-1 and TR-2, indoor air temperature presents almost always the highest values, followed by operative temperature and then of course mean radiant temperature. However, the gap between indoor temperatures of TR-1 and TR-2 increases with the progressive free-floating cooling of the indoor environment of the two Test-Rooms. During the operating systems regime, TR-1 and TR-2 trends are almost coincident, while temperatures in TR-2 tend to be higher than in TR-1 after the air conditioning switching off, in the transient interval. The average differences between Top, Tair and Tmr of the two Test-Rooms are equal to $0.62,0.57$ and $0.67^{\circ} \mathrm{C}$, respectively, with the same standard deviation value of $0.22^{\circ} \mathrm{C}$. Such results are confirmed by the trend of indoor hourly temperatures (Top, Tair and Tmr) with respect to the external dry-bulb temperature (Tout) of both Test-Rooms (Fig. 4). Indoor temperatures increase with the rise of outdoor temperature in both Test-Rooms and the higher difference between TR-2 and TR-1 is in terms of mean radiant temperature, as previously observed.

Figure 5 reports the daily average operative temperature with the standard deviation values for the two Test-Rooms during the transient period. The graph confirms the similar path described by the two Test-Rooms, but with a progressive increase of the gap between TR-2 and TR-1 when moving away from the operating regime.

Moreover, the standard deviation is generally higher for TR-2 values, with average values equal to $0.45^{\circ} \mathrm{C}$ and $0.33^{\circ} \mathrm{C}$ for TR-2 and TR-1, respectively.

Both the Test-Rooms present a more differential behavior compared to the winter scenario (Pisello et al., 2014), when a progressive monotonic free-floating cooling of the indoor environment was observed for both the buildings. In fact, the summer analysis shows alternatively decreasing (May 1st-3rd, 4th-8th and 10th12th) and increasing (May 3rd-4th and 9th-10th) trends of the daily operative temperature. This is due to the fact that the variability of outdoor weather conditions is larger in summer, thus increasing also the differential dynamics of the buildings thermal response to outdoor environmental forcing. Therefore, the optimization of building envelope performance with respect to the real external weather conditions in summer is significant in order to improve building thermal-energy efficiency and stationary characteristics are even less representative of the field dynamics than in winter conditions, requiring further investigation for design and optimization purpose.

\section{Indoor Thermal Behavior: Free-Floating Period}

The analysis of indoor thermal parameters in freefloating regime concerned the hottest summer months, i.e. from June to August 2013. In fact, the heat pumps were not working in both the Test-Rooms during the whole warm season for the purpose of this research.

Consistently with the previous analysis, the two TestRooms have similar temperature trend during the whole monitored period. TR-2 is hotter than TR-1 in terms of Top, Tair and Tmr (Fig. 6). Nevertheless, in free-floating conditions the gap between the daily average temperature values increases since they are much more affected by the daily variations of the external weather conditions. Furthermore, the indoor temperatures increase with the outdoor temperature compared to the transient regime and to the winter period (Pisello et al., 2014), when both the Test-Rooms reached an overall constant value in free-floating conditions. The monitored data show an average difference of $1.43^{\circ} \mathrm{C}$ for Tair, $1.49^{\circ} \mathrm{C}$ for Top and $1.55^{\circ} \mathrm{C}$ for $\mathrm{Tmr}$, with the standard deviation values equal to about $0.52,0.52$ and $0.53^{\circ} \mathrm{C}$, respectively, for the hourly values calculated within the free-floating range, i.e., June 1st-August 31 st (Table 1).

Table 1. Main thermal parameters for the two Test-Rooms in free-floating conditions (June 1st-August 31st, 2013)

\begin{tabular}{|c|c|c|c|c|c|c|}
\hline & \multicolumn{3}{|c|}{ Test-Room 1} & \multicolumn{3}{|c|}{ Test-Room 2} \\
\hline & Top & Tair & $T m r$ & Top & Tair & $T m r$ \\
\hline $\operatorname{Max}\left[{ }^{\circ} \mathrm{C}\right]$ & 31.09 & 31.10 & 31.15 & 33.37 & 33.31 & 33.48 \\
\hline $\operatorname{Min}\left[{ }^{\circ} \mathrm{C}\right]$ & 15.04 & 15.23 & 14.84 & 15.62 & 15.76 & 15.47 \\
\hline Ave $\left[{ }^{\circ} \mathrm{C}\right]$ & 25.56 & 25.69 & 25.43 & 27.05 & 27.12 & 26.98 \\
\hline VC $[\%]$ & 13.78 & 13.67 & 13.90 & 14.42 & 14.40 & 14.46 \\
\hline
\end{tabular}




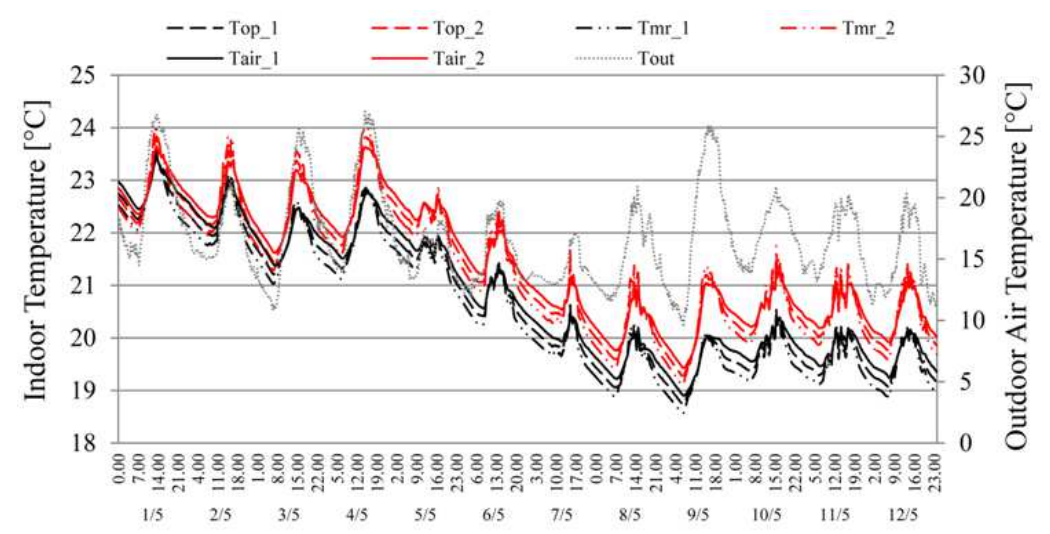

Time [hh:mm day/month]: May $01^{\text {st }}-$ May $12^{\text {th }}, 2013$

Fig. 3. Progressive cooling trend of the two Test-Rooms during the transient regime in terms of Top, Tair and Tmr with respect to outdoor dry-bulb temperature
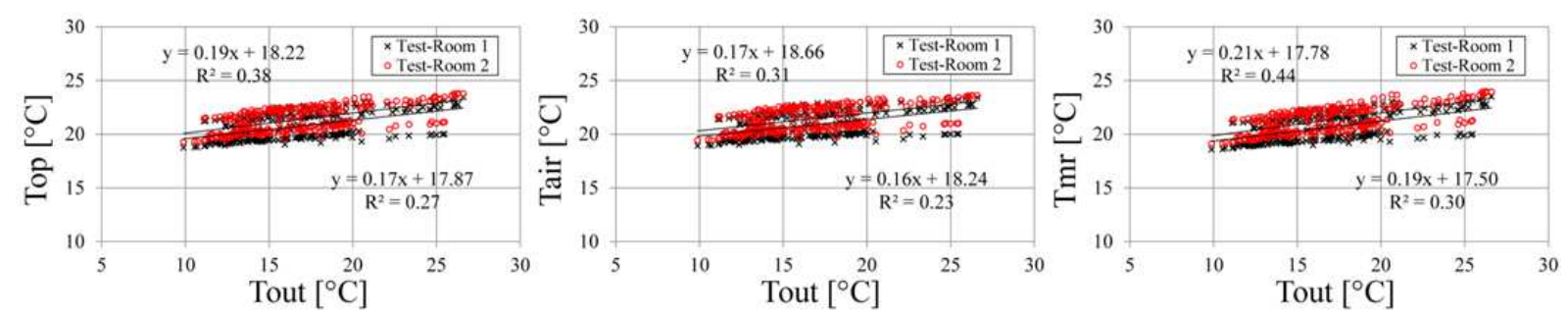

Fig. 4. Hourly temperature values (Top, Tair and Tmr) inside the two Test-Rooms with respect to external dry-bulb temperature in transient regime

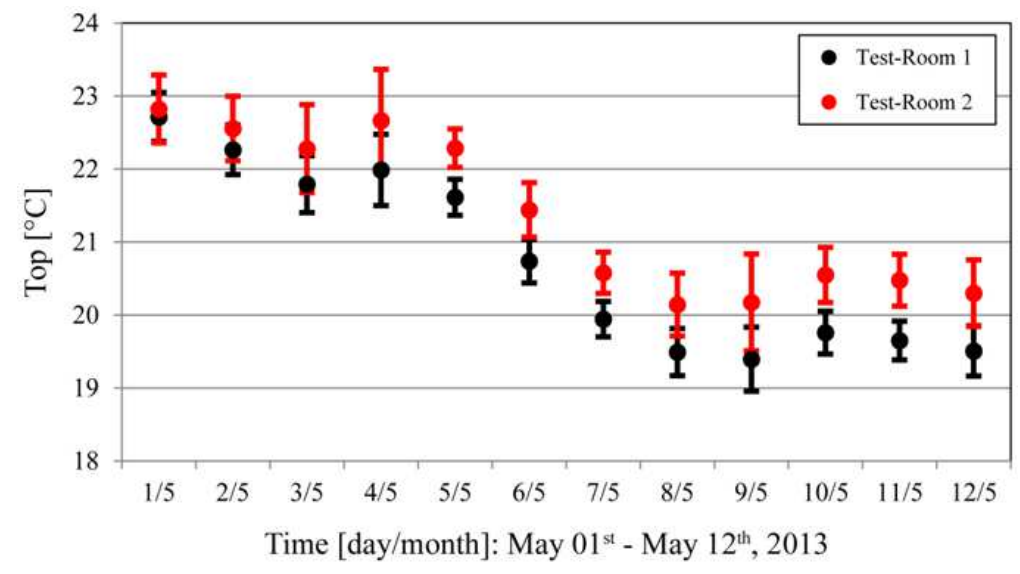

Fig. 5. Daily mean operative temperature values $( \pm \sigma)$ of the two Test-Rooms during the transient regime
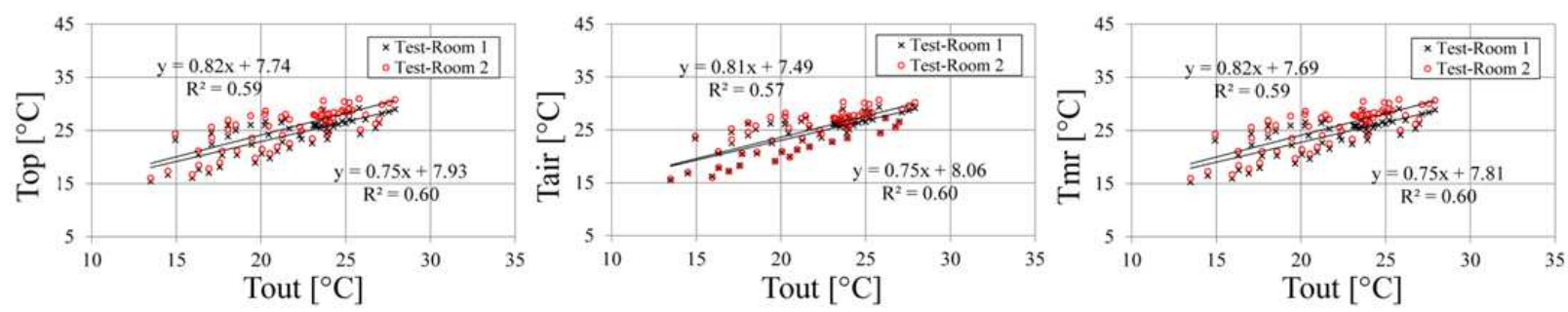

Fig. 6. Daily mean temperature values (Top, Tair and Tmr) inside the two Test-Rooms with respect to external dry-bulb temperature in free-floating regime (from June to August) 


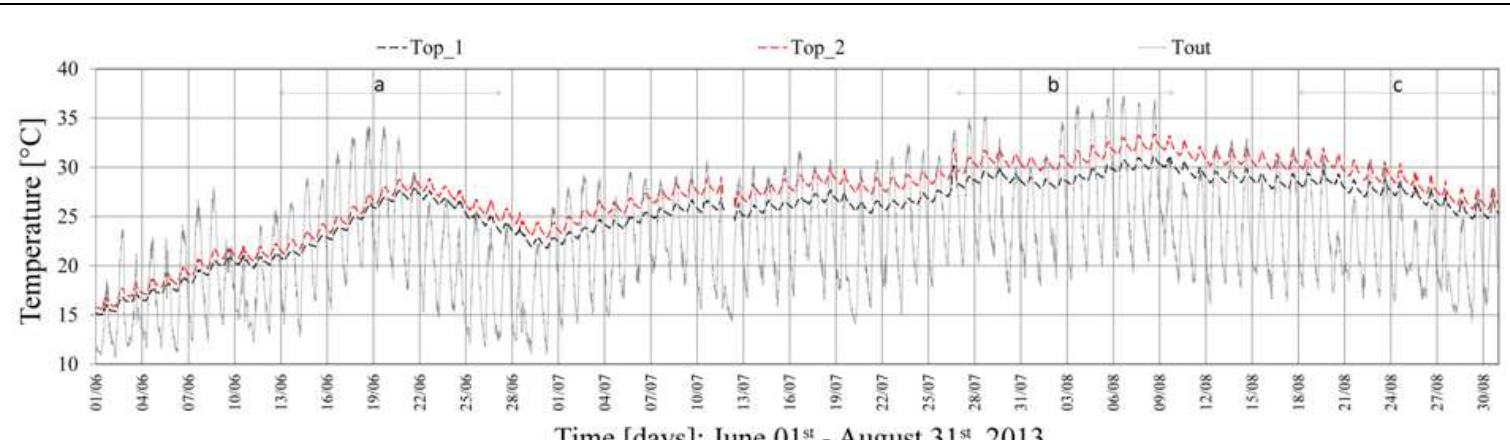

Time [days]: June $01^{\text {st }}$ - August $31^{\text {st }}, 2013$

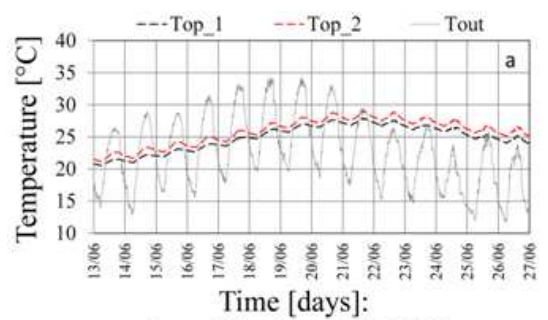

June $13^{\text {th }}-$ June $26^{\text {th }}, 2013$

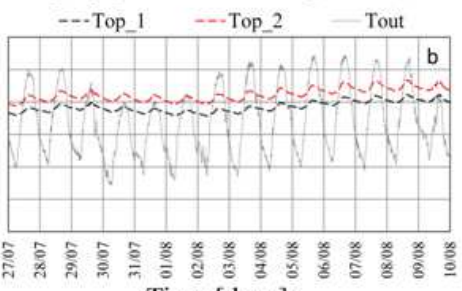

Time [days]:

July $27^{\text {th }}$ - August $09^{\text {th }}, 2013$

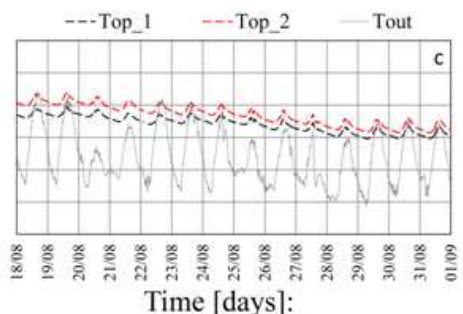

August $18^{\text {th }}$ - August $31^{\text {st }}, 2013$

Fig. 7. Comparison between operative temperature profiles of the two Test-Rooms with respect to outdoor dry-bulb temperature in free-floating regime for the whole period and zoom of three time intervals $(\mathrm{a}, \mathrm{b}$ and $\mathrm{c})$

The operative temperature (Top) profiles reported in Fig. 7 highlight the different behavior of the two TestRooms with respect to the weather conditions. As already stated, TR-2 presents a worse thermal performance compared to TR-1 during the whole summer season, with higher indoor temperatures. An opposite behavior of the Test-Rooms was registered in winter (Pisello et al., 2014), when TR-2 was detected to be slightly colder than TR-1, demonstrating the higher sensitivity to outdoor overheating trends of the TR-2 construction system. In particular, in the first period of growing outdoor temperature (Fig. 7a) the Test-Rooms show a slight temperature difference. Furthermore, in the peak days of the period phase shift between the external temperature (i.e., June 18th and 19th) and the operative temperature (i.e., June 21 st and 22 nd) is observed for both the Test-Rooms.

Further analyses of this phenomenon are carried out in the following section. Similar behavior to the first period is observed in last warm days, when outdoor air temperature decreases (Fig. 7c). Whereas, in the central and hottest days of the season (Fig. 7b), when the average of the daily maximum global solar radiation is equal to $1130 \mathrm{~W} / \mathrm{m}^{2}$, the gap between the two TestRooms increases up to a maximum difference of $2.08^{\circ} \mathrm{C}$ in terms of indoor operative temperature (July 24th). Such significant gap is due to the different reaction of TR-1 and TR-2 to the high solar radiation, which is differently absorbed by the envelopes of TR-1 and TR2. In fact, in summer conditions, when the external weather forcing is mostly influential, the effect of building envelope dynamic characteristics, i.e., superficial radiative properties and thermal capacity, is emphasized. Therefore, the Test-Rooms enlarge their mutual difference imputable to the high solar absorption of the roof bitumen membrane in TR-2 and the lower heat release capability of the external insulation layer in the same TR-2.

\section{Analysis of the Periodic Thermal Behavior in the Test-Rooms}

In order to analyze and quantify the periodical thermal behavior of the Test-Rooms, the air temperature data were studied under both the time-domain and the frequency-domain. In particular, the analysis of the temperature signals was switched from the timedomain representation (Fig. 8) to the frequencydomain representation (Fig. 9). Table 2 summarizes the results of the frequency analysis for the indoor air temperature signals of the two Test-Rooms during the free-floating regime in summer. The first peak of magnitude, which corresponds to the minimum value of frequency $\left(\mathrm{f}_{1}=5.5 \cdot 10^{-7} \mathrm{sec}^{-1}\right)$, is not relevant because it is related to the truncation of the signals after 21 days of monitoring $\left(\mathrm{T}_{1}=21\right.$ days). The maximum peak in magnitude occurs at $1.2 \cdot 10^{-5} \mathrm{sec}^{-1}$ of frequency $\left(f_{2}\right)$, which corresponds to a period $\mathrm{T}_{2}$ of $24 \mathrm{~h}$. As expected, during the three summer weeks characterized by freefloating conditions, the more relevant cycle for outdoor air temperature is the daily cycle that strongly influences the thermal behavior in both Test-Rooms. The other cycles characterized by a period of 12,8 and 
6 hours correspond to the submultiple of the daily cycle. In Fig. 9 the frequencies fi are highlighted through red colored bands in terms of both magnitude (Fig. 9a) and phase (Fig. 9b) graph. As shown in Fig. 9 and Table 2, the peaks of magnitude were found in correspondence of the same frequency values fi for each evaluated air temperature signal. On the contrary, the magnitude and the phase components of the frequency spectrum are different among the three thermal signals. In particular, the outdoor thermal forcing presents the highest peaks of magnitude followed by the indoor air temperature measured in Test-Room 2. It is evident from both the time and the frequency domain that TR-1 is able to better dampen the outdoor thermal forcing. Such effect is mainly due to the better performance of the double mass external wall system and the ventilated roof, compared to the external insulated roof and walls installed in TR-2.
Considering the phase spectrum in correspondence of frequency $f_{2}$, it is possible to determine the difference of phase in radians or seconds between the indoor thermal signals of the two Test-Rooms, as expressed in Eq. 7.

$\Delta P_{T}=P_{T-} 2\left(f_{2}\right)-P_{T-} 1\left(f_{2}\right)=0.07 \mathrm{rad}$

The phase difference of $0.07 \mathrm{rad}$ corresponds to about $15 \mathrm{~min}$ in terms of time difference. Therefore, the daily maximum air temperatures are reached about 15 min later in Test-Room 1 than in Test-Room 2, even if they are characterized by the same superficial mass of both the ceiling, the roof and the wall systems. Consistently with winter analysis and with time-domain observation, the Test-Room 1 showed to be better performing in the experimental climate context in terms of phase lag and damping of the outdoor forcing thermal and radiation signal.

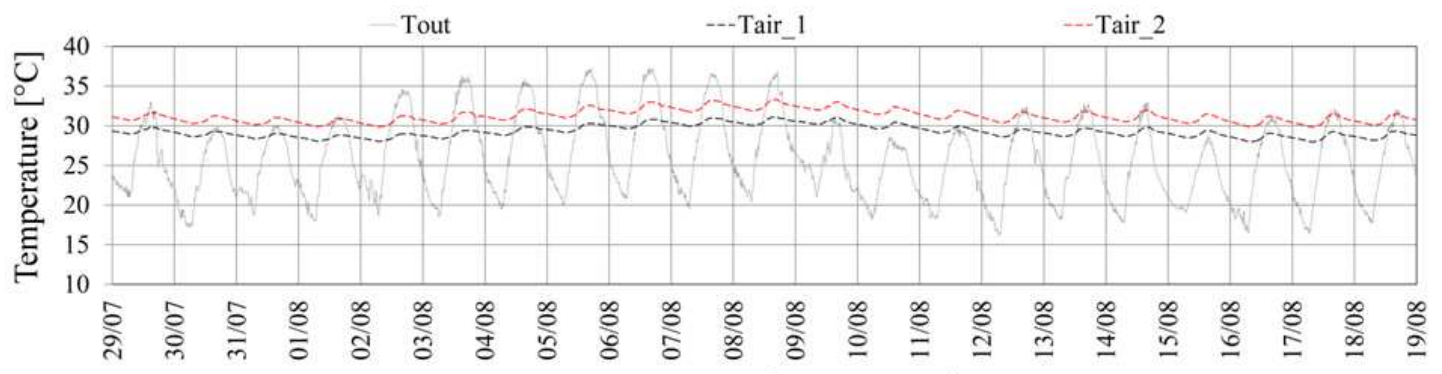

Time [days]: July $29^{\text {th }}$ - August $18^{\text {th }}, 2013$

Fig. 8. Time-domain representation of the air temperature measurements
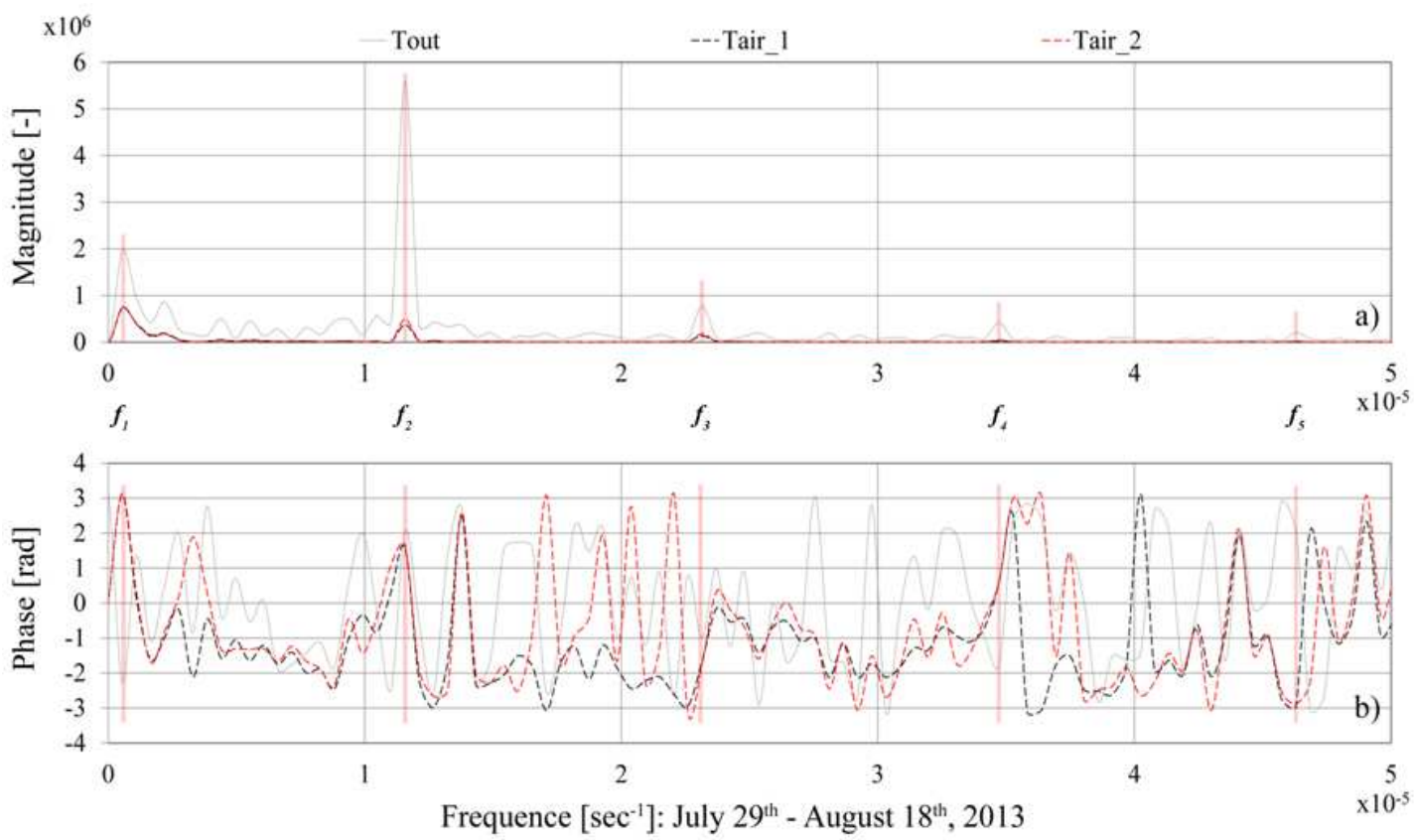

Fig. 9. Frequency-domain representation of (a) magnitude and (b) phase of the thermal signals 


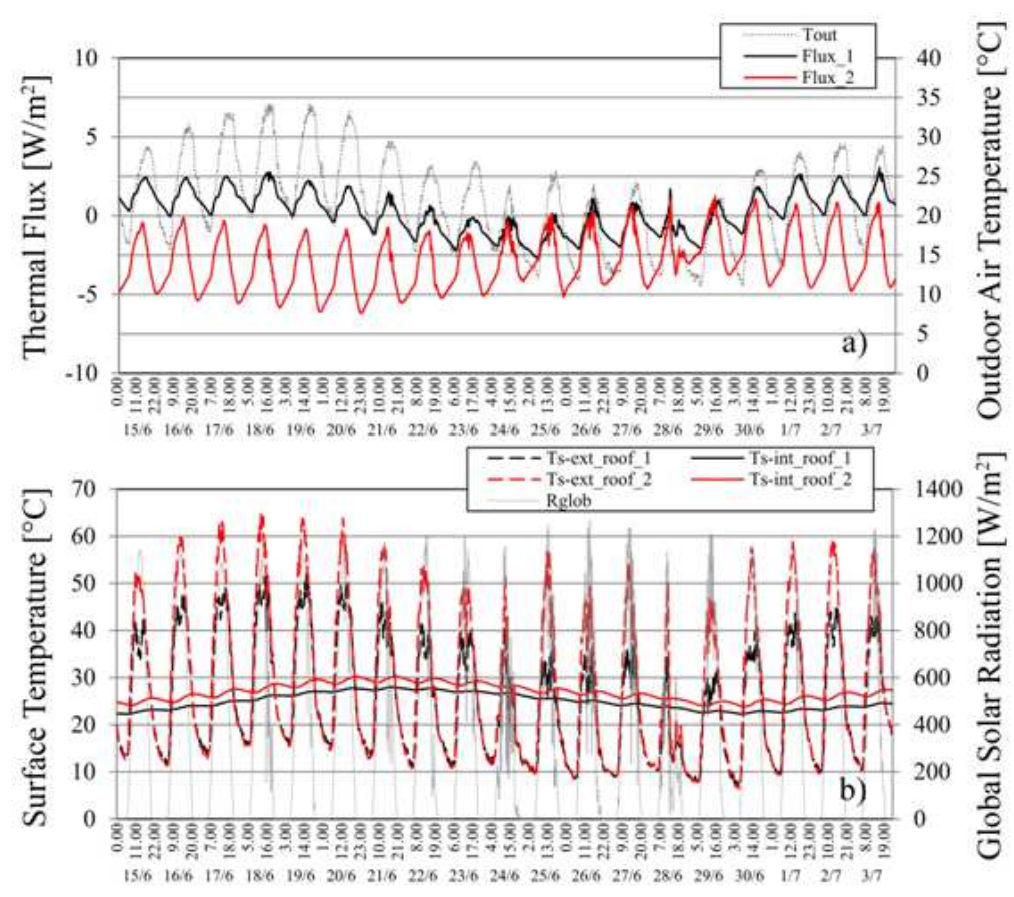

Time [hh:mm day/month]: June $15^{\text {th }}-$ July $03^{\text {rd }}, 2013$

Fig. 10. Comparison between (a) thermal fluxes and (b) internal and external surface temperatures for the roof of each Test-Room with respect to weather conditions

Table 2. Frequency analysis of the two Test-Rooms in free-floating conditions

\begin{tabular}{|c|c|c|c|c|c|c|}
\hline \multirow[b]{2}{*}{ No. cycle } & \multirow[b]{2}{*}{$\mathrm{f}\left[\mathrm{sec}^{-1}\right]$} & \multirow[b]{2}{*}{$\mathrm{T}[\mathrm{sec}]$} & \multicolumn{2}{|c|}{ Test-Room 1} & \multicolumn{2}{|c|}{ Test-Room 2} \\
\hline & & & $\mathrm{M}_{\mathrm{T}} 1[-]$ & $\mathrm{P}_{\mathrm{T}_{-}} 1[\mathrm{rad}]$ & $\mathrm{M}_{\mathrm{T}} 2[-]$ & $\mathrm{P}_{\mathrm{T}_{\mathrm{T}}} 2[\mathrm{rad}]$ \\
\hline 1 & $5.5 \cdot 10^{-7}$ & $1814400(21 \mathrm{~d})$ & $0.73 \cdot 10^{-6}$ & 3.11 & $0.75 \cdot 10^{-6}$ & 3.14 \\
\hline 2 & $1.2 \cdot 10^{-5}$ & $86400(24 \mathrm{~h})$ & $0.37 \cdot 10^{-6}$ & 1.57 & $0.49 \cdot 10^{-6}$ & 1.64 \\
\hline 3 & $2.3 \cdot 10^{-5}$ & $43215(12 \mathrm{~h})$ & $0.13 \cdot 10^{-6}$ & -1.67 & $0.18 \cdot 10^{-6}$ & -1.74 \\
\hline 4 & $3.5 \cdot 10^{-5}$ & $28802(8 \mathrm{~h})$ & $0.02 \cdot 10^{-6}$ & 0.58 & $0.04 \cdot 10^{-6}$ & 0.6 \\
\hline 5 & $4.6 \cdot 10^{-5}$ & $21603(6 \mathrm{~h})$ & $0.01 \cdot 10^{-6}$ & -2.95 & $0.02 \cdot 10^{-6}$ & -2.88 \\
\hline
\end{tabular}

\section{Analysis of Envelope Behavior: Roof Performance}

This section addresses the analysis of the thermal performance of the roof in association to the dynamic thermal behavior of the two Test-Rooms.

In order to assess the in-field dynamic behavior of the different roof configurations characterized by equal calculated stationary conditions, the thermal flux through the roof and the external and internal surface temperature of the roof have been analyzed. Thermal flux and surface temperature profiles for each Test-Room in free-floating conditions are reported in Fig. 10 for a representative summer period (June 15th-July 3rd, 2013). A behavior consistent with the previous analyses is observed. Both external and internal roof surface temperatures of TR-2 are higher than TR-1 in the whole season. In particular, the gap between the external surface temperatures of the two Test-Rooms mostly increases in mid-day hours, when the solar radiation reaches the highest values.
Furthermore, it is evident from both temperature and thermal flux profiles how the roof of TR-2 is more sensitive to outdoor temperature and solar radiation daily fluctuations. This behavior is due to the different roof technology of the two Test-Rooms. Additionally, a similar time delay between the maximum internal roof surface temperature and the maximum external roof surface temperature is detected for both the Test-Rooms. Consistently, the difference between the thermal flux through the roof of TR-2 and TR-1 is wider when the outdoor air temperature is higher, while in the coolest days the thermal flux profiles get closer. In particular, the thermal flux measured for TR-1 is almost always positive during the measured period, while the thermal flux measured for TR-2 is mainly negative.

As already stated in the previous analysis in winter conditions (Pisello et al., 2014), the increase in daily thermal peaks of the external surface of the roof of TR-2 is caused by the lower solar reflectance characteristic of 
the bituminous membrane. The reduction of the gap between TR-2 and TR-1 during the night and in cloudy or rainy days confirms the essential role of roof reflectance in reducing roof external surface temperature and thermal flux entering the roof. In particular, in summer the thermo-optical properties have the highest impact on building envelope performance due to the higher solar radiation reaching the external surface. In fact, unlike in winter conditions, also internal roof surface temperature is affected by the solar reflectance capability of the roof coating. Furthermore, the resulting higher solar absorption is perceived in the heat gains/loss through the roof. In TR-2 the measured thermal flux is mostly negative, which means that heat gains through the roof from the outside are much higher than heat losses. More in detail, the external roof surface temperature in TR-2 is higher than in TR-1 by 13.74 and $3.70^{\circ} \mathrm{C}$ in terms of maximum daily peak and daily mean temperature, respectively.

Moreover, the internal surface temperature of TR-2 is higher than in TR-1 by 2.01 and $2.35^{\circ} \mathrm{C}$, in terms of daily average values and daily peaks, respectively.

These data are confirmed by the monitored positive thermal fluxes during the same period, which are higher by $1 \mathrm{~W} / \mathrm{m}^{2}$ on average in TR-1 compared to TR-2. Findings for summer conditions are in contrast with the results obtained in winter conditions (Pisello et al., 2014), when internal roof surface temperature was higher in TR-1 than in TR-2 and thermal flux was higher in TR-2 than in TR-1. Such discrepancy is due to the greater solar radiation contribution in summer than in winter and to the difference in the optical and energy properties of the two roofs external surfaces, which effect is highlighted in hottest months. Additionally, these same properties also produce a higher thermal flux fluctuation for TR-2 that TR-1, since the daily hotter hours are characterized by a huge thermal gain and thermal flux entering the roof (Fig. 10a). While during the night, the thermal emissivity of the surface is comparable to the clay tiles one in TR-1 and they tend to reach the same surface temperature (Fig. 10b). These results are inconsistent with the values of thermal transmittance of the two Test-Rooms calculated through the stationary theoretical model from EN ISO 6946 (2007), commonly used in roof transmittance calculation in hypothetical stationary winter conditions. Such data confirm the nonnegligibility of variable boundary conditions and dynamic behavior of materials and components when assessing their thermal performance. In particular, in the case study buildings, important dynamic effects are produced by the different envelope radiative properties, e.g., solar reflectance capability and operative thermal inertia associated to layers mutual specific position, i.e., insulation layer externally or internally positioned within the multilayer wall structure.

\section{Analysis of Envelope Behavior: Walls Performance}

This section addresses the analysis of the thermal performance of South and North-facing walls in relation to the dynamic thermal behavior of the two Test-Rooms.

The equivalent analysis has been performed in the same summer period (i.e., June 15th-July 3rd, 2013) to assess the dynamic behavior of Test-Rooms walls. In particular, the internal and external wall surface temperature of both South and North-facing façade of the case study buildings have been monitored. Results are consistent with respect to the previous analysis. In fact, the internal and external surface temperatures in TR-2 are always higher than in TR-1. A smaller but consistent overheating effect is detected for the Northfacing wall of TR-2, where the external and internal surface temperatures are higher than TR-1 by 2.86 and $1.02^{\circ} \mathrm{C}$, respectively, in terms of daily peaks. In fact, the North-facing façade is less affected by the variability of outdoor weather boundary conditions. Therefore, thermal fluxes have been monitored for the same North-facing façade.

Such important difference is due to the fact that the external coat insulation in TR-2 tends to decouple the thermal behavior of the external thin layer from the internal brick blocks.

Therefore, the external thin layer of TR-2 is much more thermally stressed by solar radiation than the cavity insulated wall of TR-1, where thermal capacity, i.e. brick blocks layer, is situated in both the internal and external side. For this reason, the two Test-Rooms show again opposite but consistent behavior compared to winter (Pisello et al., 2014), when surface temperatures of TR-2 were lower than TR-1. As in winter conditions, the deviation in the dynamic behavior of TR-1 and TR-2 is due to the different multilayer configuration and in particular to the differential position of the insulation layer (Pisello et al., 2014) contributing to the effective collaborating mass Vs outdoor thermal stresses.

Further analyses have been carried out in terms of moisture behavior through the envelope.

Figure 11 reports the hourly profiles of relative humidity together with the indoor air temperature profiles of the two Test-Rooms, during some weeks of freefloating regime (July 13th-August 5th, 2013). The graph points out the same trend but different behavior of TR-1 and TR-2 in terms of moisture. In fact, both the TestRooms are characterized by air Relative Humidity $(\mathrm{RH})$ out of the comfort ranges, even with high outdoor temperatures. Relative humidity progressively decreases with increasing air temperature, but with a relatively lower gradient. However, a large gap is found between the two Test-Rooms, which show maximum and average values of 
RH equal to 84.24 and $75.60 \%$, respectively, for TR- 1 and 93.14 and $86.32 \%$ for TR-2. The gap, i.e., about $10 \%$, is almost constant during the whole considered period, meaning that the difference between the two TestRooms is imputable to their intrinsic passive behavior of opaque envelope systems and their mass transfer capability. In fact, findings are consistent with the winter behavior (Pisello et al., 2014), since TR-2 shows always the higher value of in free-floating conditions, due to the lower transpiration capability of the external coat insulation panel. The sudden decrease of relative humidity and increase of indoor air temperature recorded on July 26th (Fig. 11) are due to the opening of door and window in both Test-Rooms.

Such behavior also affects internal surface temperatures of Test-Rooms walls. Figure 12 reports the internal surface temperature profiles for the South-facing (top and bottom) and North-facing wall (only top) of each Test-Room in free-floating conditions for a representative summer period (June 16th-July 10th, 2013). Consistently with previous results, walls surface temperatures of TR-2 are significantly higher than TR-1 and the gap slightly increases with the growing of outdoor air temperature. Nevertheless, in the first analyzed days (June 16th-25th, 2013) the North-wall surface temperature of TR-2 is lower than all the surface temperatures of TR-1. Such behavior is imputable to high humidity rate in TR-2, which is mostly perceived in the North-facing wall where solar radiation contribution is lower. In fact, superficial condensation is observed on the lower part of walls, caused by the non-transpiring structure of TR-2, which influences the envelope thermal insulation behavior (Pisello et al., 2014). As expected, in TR-2 the South-wall surface temperature on top $(\mathrm{H})$ presents the highest values, followed by the South-wall surface temperature on bottom (L) and the North-wall temperature, due to humidity rate and solar radiation reaching the wall outermost layer.

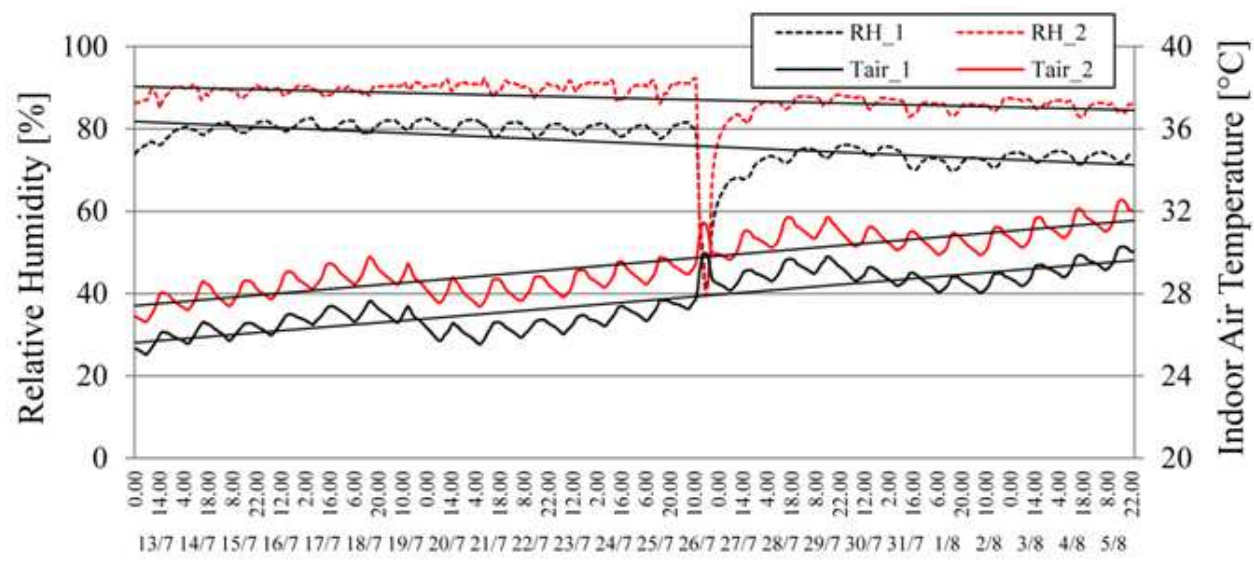

Time [hh:mm day/month]: July $13^{\text {th }}$ - August $05^{\text {th }}, 2013$

Fig. 11. Indoor relative humidity and air temperature behavior of each Test-Room

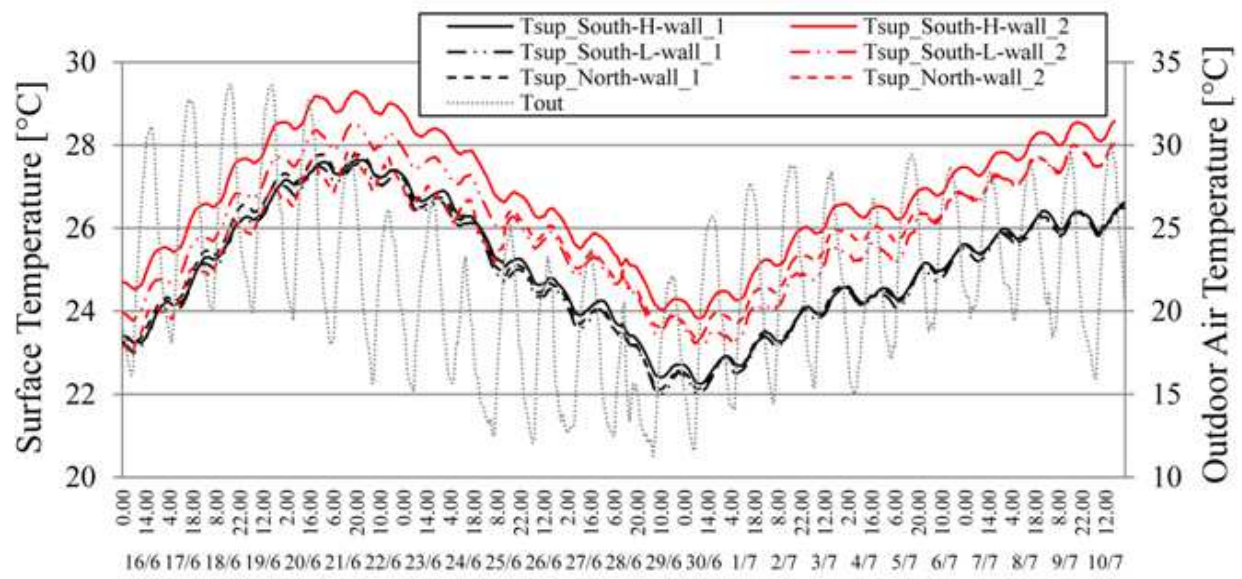

Time [hh:mm day/month]: June $16^{\text {th }}-$ July $10^{\text {th }}, 2013$

Fig. 12. Internal surface temperature profiles of TR-1 and TR-2 with respect to outdoor air temperature 
However, in a second period of increasing outdoor temperature (June 30th-July 6th, 2013) the North-wall temperature exceeds the South-wall temperature on bottom. Conversely, in TR-1 the surface temperatures of South-facing wall and North-facing wall are almost overlapped. Indeed, the different wall technology presenting greater transpiration capability and thermal capacity allows a more uniform temperature distribution compared to TR-2 which is, again, more sensitive to solar forcing even on the walls. The interesting result here is that, despite the equivalent solar reflectance capability of the external wall layers of the test-rooms, TR-2 still presents this higher sensitivity like in the case of the roof. Such results are also consistent with the previously analyzed values of mean radiant temperature, which has a higher variability in TR-2. In fact, the maximum and average mean radiant temperature is equal to 27.91 and $21.96^{\circ} \mathrm{C}$, respectively, in TR-1 and 30.30 and $23.22^{\circ} \mathrm{C}$, respectively, in TR-2.

\section{Conclusion}

In several national regulations, the design process and the assessment of buildings thermal-energy performance are based on stationary hypotheses of the main environmental forcing. However, dynamic boundary conditions are well acknowledged to affect building overall thermal-energy behavior. In particular, in summer the weather forcing, e.g., mainly outdoor fluctuating temperature and solar radiation, represents a key variable influencing indoor environment perception. Therefore, the exhaustive analysis of the complex thermal-energy behavior of buildings requires increasingly sophisticated dynamic investigation tools.

In order to study the dynamic hygro-thermal behavior of buildings in summer conditions, this paper analyzed the results of a long-term continuous monitoring campaign of two prototype buildings, i.e., Test-Rooms. The two Test-Rooms were designed in order to present the same calculated stationary thermal properties, therefore they should behave the same if the stationary assumption is correct. However, by keeping this stationary equivalence, they present different envelope materials and technologies, therefore different dynamic behavior. The aim of this paper was to assess the dynamic performance of the two buildings by considering continuously monitored hygro-thermal parameters in summer conditions. The study is part of a more extensive experimental research aimed at evaluating the dynamic hygro-thermal and energy performance of different envelope typologies, which is affected by the variability of the external boundary conditions. In particular, external insulation systems, typical of new or recently retrofitted buildings in Italy like Test-Room 2, are compared to traditional double brick layers and ventilated opaque envelope systems like Test-Room 1.
The main results showed a non-negligible difference between the dynamic behavior of the two Test-Rooms in summer conditions, in terms of hygro-thermal performance. Such discrepancy was found to be higher if compared to winter conditions. In general, the Test-Room with double brick block layer and internal cavity insulation (TR-1) presents a better hygro-thermal behavior in summer conditions than the Test-Room with external coat insulation, consistently with the winter analysis previously carried out by the authors. In transient conditions, an average difference between the two TestRooms of $0.62,0.57$ and $0.67^{\circ} \mathrm{C}$ is detected in terms of Top, Tair and Tmr, respectively. In free-floating conditions, TR2 is showed to be hotter than TR-1, with higher average difference equal to $1.43^{\circ} \mathrm{C}$ for Tair, $1.49^{\circ} \mathrm{C}$ for Top and $1.55^{\circ} \mathrm{C}$ for Tmr. The larger difference showed in terms of mean radiant temperature demonstrated the key role played by the material stratigraphy in affecting indoor thermal comfort conditions.

The frequency analysis confirms such results. Additionally, the daily cycle is the most relevant cycle for the outdoor air temperature varying from 16.20 to $29.12^{\circ} \mathrm{C}$ and, consequently, for the indoor air temperature of both Test-Rooms from 25.17 to $26.25^{\circ} \mathrm{C}$ on the average for TR-1 and from 26.50 to $27.84^{\circ} \mathrm{C}$ on the average for TR-2.

The daily maximum external roof surface temperature in TR-2 is higher than in TR-1 by $13.74^{\circ} \mathrm{C}$. Consistently, the internal roof surface temperature of TR-2 is detected to be higher than TR-1 by $2.01^{\circ} \mathrm{C}$, in terms of daily average values. Such discrepancy is motivated by the different solar reflectance capability of the roof technologies. Moreover, the external and internal maximum daily surface temperatures on the top of Southfacing wall in TR-2 are higher than in TR-1 by 13.93 and $1.58^{\circ} \mathrm{C}$, respectively. A smaller but consistent overheating effect is detected for the North-facing wall of TR-2 compared to TR-1. As in winter conditions, the deviation in the dynamic behavior of Test-Rooms walls is due to their different real contributing thermal capacity.

The moisture analysis showed high relative humidity values even with high outdoor temperatures for both the Test-Rooms. However, TR-2 presents constantly higher values than TR-1 with an average percentage increase of about $10 \%$, due to its lower transpiration capability and thermal mass.

Therefore, the main findings of this study are in general consistent with the previous winter analysis and depict even greater discrepancies in the dynamic hygrothermal behavior of the two Test-Rooms in summer conditions. Such difference in Test-Rooms performance is mainly imputable to the higher solar reflectance capability and the ventilated nature of the upper roof layer of TR-1. In fact, the influence of radiative properties is mostly perceived in summer months, when the external weather forcing is highlighted. Moreover, the different thermal 
mass of Test-Rooms walls technologies plays a key role in their performance, involving a lower heat capacity and transpiration capability of TR-2. TR-2, also according to the winter analysis, demonstrated to be in general the most sensitive to the external weather parameters variation, showing to be more potentially energy demanding in both cooling and heating need.

\section{Acknowledgement}

The authors' acknowledgements are due to Cassa di Risparmio di Perugia Foundation, for supporting the construction of the experimental field through the BAIO (Italian acronym for Indoor-Outdoor Environmental Comfort) project. Additionally, the authors would like to thank all the industrial partners of BAIO project. The first author's acknowledgments are also due to the "CIRIAF program for UNESCO" in the framework of the UNESCO Chair "Water Resources Management and Culture", for supporting her research.

\section{Authors' Contributions}

Anna Laura Pisello is an assistant professor leading the work development and the experimental activities. Gloria Pignatta, a post-doc researcher and Cristina Piselli, a Ph.D. student, contributed to the experimental campaign and paper writing. Veronica Lucia Castaldo, a Ph.D. student, contributed to the field monitoring and paper reviewing. Franco Cotana is the professor supervising the entire research.

\section{Ethics}

The authors declare no ethical issues that may arise after the publication of this manuscript.

\section{References}

Alcamo, G. and M. De Lucia, 2014. A new test cell for the evaluation of thermo-physical performance of facades building components. Int. J. Sustainable Energy, 33: 954-962.

DOI: $10.1080 / 14786451.2013 .796943$

Asdrubali, F., M. Bonaut, M. Battisti and M. Venegas, 2008. Comparative study of energy regulations for buildings in Italy and Spain. Energy Build., 40: 1805-1815. DOI: 10.1016/j.enbuild.2008.03.007

Baker, P.H. and H.A.L. Van Dijk, 2008. PASLINK and dynamic outdoor testing of building components. Build. Environ., 43: 143-151.

DOI: $10.1016 /$ j.buildenv.2006.10.009

Bond, D.E.M., W.W. Clark and M. Kimber, 2013. Configuring wall layers for improved insulation performance. Applied Energy, 112: 235-245.

DOI: 10.1016/j.apenergy.2013.06.024
Coma, J., G. Pérez, C. Solé, A. Castell and L.F. Cabeza, 2016. Thermal assessment of extensive green roofs as passive tool for energy savings in buildings. Renew. Energy, 85:1106-1115. DOI: $10.1016 /$ j.renene.2015.07.074

De Gracia, A., C. Fernández, A. Castell, C. Mateu and L.F. Cabeza, 2015. Control of a PCM ventilated facade using reinforcement learning techniques. Energy Build., 106: 234-242. DOI: $10.1016 /$ j.enbuild.2015.06.045

De Lieto Vollaro, R., C. Guattari, L. Evangelisti, G. Battista and E. Carnielo et al., 2015. Building energy performance analysis: A case study. Energy Build., 87: 87-94. DOI: $10.1016 /$ j.enbuild.2014.10.080

OJEU, 2010. Directive 2010/31/EU of the European parliament and of the council of 19 May 2010 on the energy performance of buildings. Official Journal of the European Union.

OJEU, 2012. Directive 2012/27/EU of the European parliament and of the council of 25 October 2012 on energy efficiency, amending directives 2009/125/EC and 2010/30/EU and repealing Directives 2004/8/EC and 2006/32/EC. Official Journal of the European Union.

Doya, M., E. Bozonnet and F. Allard, 2012. Experimental measurement of cool facades' performance in a dense urban environment. Energy Build., 55: 42-50.

DOI: $10.1016 /$ j.enbuild.2011.11.001

EN ISO 6946, 2007. Building components and building elements. Thermal resistance and thermal transmittance. Calculation method.

Evangelisti, L., G. Battista, C. Guattari, C. Basilicata and R. De Lieto Vollaro, 2014. Influence of the thermal inertia in the European simplified procedures for the assessment of buildings' energy performance. Sustainability, 6: 4514-4524. DOI: 10.3390/su6074514

Grynning, S., B. Time and B. Matusiak, 2014. Solar shading control strategies in cold climates-Heating, cooling demand and daylight availability in office spaces. Solar Energy, 107: 182-194.

DOI: 10.1016/j.solener.2014.06.007

Hong, T., S. D'Oca, S.C. Taylor-Lange, W.J.N. Turner and Y. Chen et al., 2015. An ontology to represent energy-related occupant behavior in buildings. Part II: Implementation of the DNAS framework using an XML schema. Build. Environ., 94: 196-205. DOI: $10.1016 /$ j.buildenv.2015.08.006

Kolokotsa, D. and M. Santamouris, 2015. Review of the indoor environmental quality and energy consumption studies for low income households in Europe. Sci. Total Environ., 536: 316-330. DOI: $10.1016 /$ j.scitotenv.2015.07.073

Kossecka, E. and J. Kosny, 2002. Influence of insulation configuration on heating and cooling loads in a continuously used building. Energy Build., 34: 321-331. DOI: 10.1016/S0378-7788(01)00121-9 
Kotsiris, G., A. Androutsopoulos, E. Polychroni and P.A. Nektarios, 2012. Dynamic U-value estimation and energy simulation for green roofs. Energy Build., 45: 240-249. DOI: 10.1016/j.enbuild.2011.11.005

Leal, V. and E. Maldonado, 2008. The role of the PASLINK test cell in the modelling and integrated simulation of an innovative window. Build. Environ., 43: 217-227. DOI: 10.1016/j.buildenv.2006.10.025

Navarro, L., A. De Gracia, A. Castell, S. Álvarez and L.F. Cabeza, 2015. PCM incorporation in a concrete core slab as a thermal storage and supply system: Proof of concept. Energy Build., 103: 70-82. DOI: 10.1016/j.enbuild.2015.06.028

Peruzzi, L., F. Salata, A. De Lieto Vollaro and R. De Lieto Vollaro, 2014. The reliability of technological systems with high energy efficiency in residential buildings. Energy Build., 68: 19-24. DOI: $10.1016 /$ j.enbuild.2013.09.027

Pisello, A.L., C. Piselli and F. Cotana, 2015. Influence of human behavior on cool roof effect for summer cooling. Build. Environ., 88: 116-128. DOI: 10.1016/j.buildenv.2014.09.025

Pisello, A.L., F. Cotana, A. Nicolini and C. Buratti, 2014. Effect of dynamic characteristics of building envelope on thermal-energy performance in winter conditions: In field experiment. Energy Build., 80: 218-230. DOI: 10.1016/j.enbuild.2014.05.017

Revel, G.M., M. Martarelli, M. Emiliani, L. Celotti and R. Nadalini et al., 2014. Cool products for building envelope- Part II: experimental and numerical evaluation of thermal performances. Solar Energy, 105: 780-791. DOI: 10.1016/j.solener.2014.02.035

Saber, H.H., W. Maref, G. Gnanamurugan and M. Nicholls, 2015. Energy retrofit using vacuum insulation panels: An alternative solution for enhancing the thermal performance of wood-frame walls. J. Build. Phys., 39: 35-68. DOI: $10.1177 / 1744259113505748$

Salata, F., A. De Lieto Vollaro and A. Ferraro, 2014a. An economic perspective on the reliability of lighting systems in building with highly efficient energy: A case study. Energy Convers. Manage., 84: 623-632. DOI: 10.1016/j.enconman.2014.04.063

Salata, F., A. De Lieto Vollaro and R. De Lieto Vollaro, 2014b. A case study of technical and economic comparison among energy production systems in a complex of historic buildings in Rome. Energy Proc., 45: 482-491.

DOI: $10.1016 /$ j.egypro.2014.01.052

Stazi, F., E. Tomassoni, C. Bonfigli and C. Di Perna, 2014. Energy, comfort and environmental assessment of different building envelope techniques in a Mediterranean climate with a hot dry summer. Applied Energy, 134: 176-196.

DOI: 10.1016/j.apenergy.2014.08.023
Synnefa, A. and M. Santamouris, 2012. Advances on technical, policy and market aspects of cool roof technology in Europe: The cool roofs project. Energy Build., 55: 35-41. DOI: 10.1016/j.enbuild.2011.11.051

Tariku, F., K. Kumaran and P. Fazio, 2015. Application of a Whole-Building Hygrothermal model in energy, durability and indoor humidity retrofit design. J. Build. Phys., 39: 3-34.

DOI: $10.1177 / 1744259114522400$

Znouda, E., N. Ghrab-Morcos and A. Hadj-Alouane, 2007. Optimization of Mediterranean building design using genetic algorithms. Energy Build., 39: 148-153. DOI: 10.1016/j.enbuild.2005.11.015

\section{Nomenclature}

TR:

Test-Room, monitored prototype building

TR-1, TR-2: $\quad$ Test-Room 1 and 2, respectively

$\mathrm{RH}$ : Indoor air relative humidity [\%]

Tair: Indoor air temperature $\left[{ }^{\circ} \mathrm{C}\right]$

Tair_1, Tair_2: Indoor air temperature in Test-Room 1 and 2 , respectively $\left[{ }^{\circ} \mathrm{C}\right]$

Tmr: Indoor mean radiant temperature $\left[{ }^{\circ} \mathrm{C}\right]$

Top: $\quad$ Indoor operative temperature $\left[{ }^{\circ} \mathrm{C}\right]$

Ts-ext, Ts-int: External and internal surface temperature, respectively $\left[{ }^{\circ} \mathrm{C}\right]$

Flux: $\quad$ Thermal flux $\left[\mathrm{W} / \mathrm{m}^{2}\right]$

Tout: $\quad$ Outdoor air temperature $\left[{ }^{\circ} \mathrm{C}\right]$

Rglob: Global solar radiation $\left[\mathrm{W} / \mathrm{m}^{2}\right]$

VC: $\quad$ Coefficient of variation [-]

$\sigma: \quad$ Standard deviation $[-]$

$\mathrm{T}(t): \quad$ Thermal time function

$\Theta(f): \quad$ Thermal frequency function, i.e. Fourier transform

$\Theta_{\mathrm{r}}: \quad$ Real part of the complex number $\Theta$

$\Theta_{\mathrm{i}}$ : $\quad$ Imaginary part of the complex number $\Theta$

$\mathrm{M}_{\mathrm{T}}$ : $\quad$ Magnitude/amplitude of the thermal signal [-]

$\mathrm{M}_{\mathrm{T} \_}$1, $\mathrm{M}_{\mathrm{T} \_}$2: Magnitude/amplitude of Test-Room 1 and 2, respectively [-]

$\mathrm{P}_{\mathrm{T}}$ : $\quad$ Phase/angle of the thermal signal [rad]

$\mathrm{P}_{\mathrm{T} \_}$1, $\mathrm{P}_{\mathrm{T} \_}$2: $\quad$ Phase/angle of a signal of Test-Room 1 and 2, respectively [rad]

$\mathrm{f}_{\mathrm{s}}$ : $\quad$ Frequency sampling of a signal $\left[\mathrm{sec}^{-1}\right]$

$f_{\max }$ : $\quad$ Maximum frequency included in a signal $\left[\mathrm{sec}^{-1}\right]$

$\mathrm{T}_{\mathrm{i}}: \quad \mathrm{i}^{\text {th }}$ period [sec]

$\mathrm{f}_{\mathrm{i}}$ : $\quad \mathrm{i}^{\text {th }}$ frequency $\left[\mathrm{sec}^{-1}\right]$

$\mathrm{N}$ : Maximum number of cycles considered $[-]$ 